\title{
ИЗБИРАТЕЛЬНОЕ ЗАКОНОДАТЕЛЬСТВО КАК РАЗНОВИДНОСТЬ ПОЛИТИЧЕСКОЙ ТЕХНОЛОГИИ
}

\author{
E. В. Махора \\ Московский гуманитарный университет
}

Аннотация: В статье рассмотрены этапы трансформации регионального избирательного законодательства в России. Анализируются выборы глав регионов, состоявшиеся в 2018 г., и применявшиеся на них политические технологии.

Ключевые слова: избирательное законодательство; политическая технология; российские выборы; российская политика; региональные выборы

\section{ELECTORAL LEGISLATION AS A TYPE OF POLITICAL TECHNOLOGY}

\author{
E. V. Makhora \\ Moscow University for the Humanities
}

Abstract: The article describes the stages of transformation of the regional electoral legislation in Russia. The author analyzes the 2018 elections of Heads of regions, as well as the political technologies that were used in the course of those elections.

Keywords: electoral legislation; political technology; Russian elections; Russian politics; regional elections

В политике часто для того, чтобы достигнуть определенных целей применяются однотипные приемы и способы деятельности. Данные приемы и способы принято называются политическими технологиями. Одной из разновидностью политических технологий являются избирательные технологии. Избирательная технология - это совокупность средств, способов и приемов, используемых при организации и проведении избирательных кампаний и направленных на достижение предвыборных целей отдельных кандидатов или политических партий в соответствующей электоральной ситуации (Ланцов, 2018: 274).

Грамотное применение политических технологий повышает эффективность политической деятельности и позволяет достигать поставленной цели оптимальным образом (Шабров, 2012: 330).

Согласно части 1 статьи 131 Конституции Российской Федерации структура органов местного самоуправления определяется населением самостоятельно, а в силу пункта 4 части 1 статьи 44 Федеральный закон «Об общих 
Научные труды Московского гуманитарного университета

2019 № 1

принципах организации местного самоуправления в Российской Федерации» от 06.10.2003 № 131-Ф3 порядок формирования представительных органов местного самоуправления определяется уставами муниципальных образований (Юсубов, 2015: 45).

Периодическое обновление выборных органов государственной власти является важным показателем демократии и гарантией подлинного народовластия, провозглашенного статьи 3 Конституции Российской Федерации, и обеспечивает осуществление республиканской формы правления, своевременную ротацию властного аппарата, постоянное и активное участие граждан в управлении делами государства. Данные положения необходимо реализовывать как на федеральном, так и на региональном уровне (Мамаева, 2015: 25).

Необходимо отметить, что в системе органов государственной власти субъекта Российской Федерации центральное место занимает региональная исполнительная власть.

С 1992 г. по настоящее время произошла настоящая эволюция в формировании корпуса глав регионов. Рассмотрим подробно эту эволюцию по этапам, которые выделил Р. С. Мухаментов:

Первый этап - 1992-1996 гг. Указанный период характеризуется тем, что отсутствовала единая система формирования региональной исполнительной власти в Российской Федерации. То есть часть глав регионов назначалась главой государства, часть - избирались населением (Мухаметов, 2016: 45-47).

Bторой этап - 1996-2005 гг. Главной характеристикой второго этапа являлись повсеместные прямые выборы глав регионов.

В 1995 г. вышел Указ Президента «0 выборах в органы государственной власти субъектов Российской Федерации». В данном документе было указано, что выборы глав региональных администраций, которых назначил Президент Российской Федерации, состоятся в декабре 1996 г. Политологи считают, что появление вышеуказанного документа - вынужденная мера, поскольку федеральным властям пришлось принимать во внимание позицию губернаторов, настаивающих на прямых выборах (Мухаметов, 2016: 45-47).

Третий этап - 2005-2012 гг. На этом этапе применялась система наделения полномочиями губернаторов региональными парламентами по представлению Президента Российской Федерации. Основной особенностью данной системы являлось то, что губернаторы, по сути, назначались федеральным центром и несли перед ним прямую политическую ответственность.

Когда Президентом Российской Федерации являлся Д. А. Медведев (2008-2012), право подбора кандидатов в губернаторы перешло к федеральному руководству партии, которая одержала победу на выборах в парламент субъекта Российской Федерации. 
Политологи полагают, что основной причиной, которая побудила федеральный центр к указанной мере, стало влияние, которое главы регионов оказывают на итоги федеральных выборов в субъектах страны.

Данное нововведение заключалось в значительном повышении роли политических партий (Мухаметов, 2016: 45-47).

Четвертый этап начался в 2012 г. и продолжается по настоящее время. Он характеризуется тем, что к формированию корпуса глав регионов применяется смешанная система. То есть одни губернаторы избираются на прямых выборах, другие - утверждаются парламентами субъектами Российской Федерации.

Важными датами этого этапа стали: 15 декабря 2011 г. (когда В. В. Путин сделал заявление о возможном восстановлении прямых губернаторских выборов) и 22 декабря 2011 г. (когда в обращении к Федеральному Собранию Российской Федерации Д. А. Медведев предложил пакет политических реформ, в список которых входило возвращение прямых выборов глав регионов).

Пакет реформ являлся, можно сказать, ответом российских властей на требования людей о демократизации, которые прозвучали во время митинга на Болотной площади 10 декабря 2011 года.

Таким образом, восстановление губернаторских выборов было первой реформой, которую предложили российские власти после оглашения не очень хороших для них итогов выборов депутатов Государственной думы Российской Федерации. Как следствие, в апреле 2012 г. был принят Федеральный Закон от 02.05.2012 № 40 «З « внесении изменений в Федеральный закон «Об общих принципах организации законодательных (представительных) и исполнительных органов государственной власти субъектов Российской Федерации» и Федеральный закон «Об основных гарантиях избирательных прав и права на участие в референдуме граждан Российской Федерации», который возвратил прямые выборы глав регионов.

В 2013 г. в избирательное законодательство были внесены поправки, которые позволили субъектам Российской федерации заменить прямые губернаторские выборы голосованием в парламенте.

Первым регионом, отказавшимся от прямых выборов президента республики, стал Дагестан. Второй регион - Ингушетия, третий - Северная Осетия. Одной из основных причин для данного шага российские эксперты называют угрозу межэтнических конфликтов и сложные межэлитные противоречия (Мухаметов, 2016: 45-47).

Далее рассмотрим выборы глав регионов в 2018 г.

В единый день голосования 9 сентября 2018 г. прямые выборы губернаторов прошли в 22 регионах Российской Федерации (Эксперт назвал ... , 2018: Электр. ресурс). 
Научные труды Московского гуманитарного университета 2019 № 1

Во всех субъектах кандидатов на должности глав регионов выдвигали избирательные объединения. В Москве, Кемеровской и Омской областях также было предусмотрено самовыдвижение.

В общей сложности были выдвинуты 172 кандидата $(147$ - от 34 политических партий и 25 - в порядке самовыдвижения). Из них избирательными комиссиями субъектов Российской Федерации были зарегистрированы 102 претендента - 99 от 16 партий и 3 самовыдвиженца.

Наибольшее количество кандидатов баллотировалось от партии ЛДПР (20 чел.), партии «Единая Россия» и «Справедливой России» (по 19 чел.), КПРФ (17 чел.) и от Партии роста (7 чел.).

Руководитель экспертного совета Экспертного института социальных исследований (ЭИСИ) Г. С. Кузнецов отметил, что не все главы регионов изначально были в одинаково благоприятных стартовых условиях. Например, губернатору Московской области А. Ю. Воробьеву пришлось вести кампанию на фоне так называемых «мусорных протестов».

Кроме того, Г. С. Кузнецов полагает, что единый день голосования 2018 года «не настолько предсказуем, как мы привыкли видеть по сравнению с предыдущими годами» (Эксперт назвал ... , 2018: Электр. ресурс).

Глава Всероссийского центра изучения общественного мнения (ВЦИOM) В. В. Федоров полагает, что в ходе региональных кампаний в 2018 г. оппозиционные партии не проявили себя достаточно ярко то есть не использовали потенциал недовольства избирателей в том числе планируемым повышением пенсионного возраста (Глава ВЦИОМ ... , 2018: Электр. ресурс).

По итогам единого дня голосования, в первом туре не сумели победить губернаторы четырех регионов (Владимировская область, Приморский край, Республика Хакасия, Хабаровский край).

В последний раз выборы в два тура проходили в Российской Федерации в 2015 г. Тогда кандидат от партии КПРФ С. Г. Левченко одержал победу над действующим главой Иркутской области С. В. Ерощенко.

Однако, сразу несколько вторых туров на губернаторских кампаниях явление для современной России фактически уникальное. Такого не было с 2004 г., когда был принят закон об отмене прямых выборов губернаторов (Назад в нулевые ... , 2018: Электр. ресурс).

Во Владимирской области на выборах одержал победу кандидат от партии ЛДПР В. Сипягин (57,03\%). Таким образом, кандидат от партии «Единой России» С. Ю. Орлова (была губернатором Владимировской области с 2013 г.) проиграла.

Вероятный проигрыш Орловой накануне выборов предсказывали социологи и не исключали «протестного голосования».

В Хабаровском крае проиграл кандидат от партии «Единая Россия» 
В. И. Шпорт (был губернатором 9 лет) депутату Государственной Думы от партии ЛДПР С. И. Фургалу (Сергей Фургал ... , 2018: Электр. ресурс).

После отмены результатов второго тура выборов глав регионов в Приморском крае произошла смена врио главы региона.

Выборы губернатора Приморского края прошли в два тура - 9 сентября и 16 сентября 2018 г. Во второй тур вышли врио главы региона А. В. Тарасенко от партии «Единой России» и А. С. Ищенко - кандидат от партии КПРФ.

По официальным данным, победу одержал кандидат от партии «Единая Россия», разница в набранных голосах составила около 1,5\%. Однако, затем Избирательная комиссия Приморского края по рекомендации Центральной избирательной комиссии Российской Федерации итоги выборов отменила из-за массовых нарушений, которые не позволили определить настоящего победителя выборов (Антикризисный глава ... , 2018: Электр. ресурс).

Политологи утверждают, что после объявления результатов и отмены итогов выборов снова выдвигать кандидатуру А. В. Тарасенко было бы «контрпродуктивно».

Кроме того, против участия А. В. Тарасенко в новых выборах выступила и Председатель Центральной избирательной комиссии Российской Федерации Э. А. Памфилова. Она предлагала отказаться от новых выборов и его оппоненту А. С. Ищенко.

По мнению политолога А. А. Пожалова, одна из основных причин принятия данного решения - это кратчайшие сроки новой избирательной кампании. Также, он отметил, что фигура нового кандидата должна была быть понятной, с одной стороны, избирателю, с другой - местным элитам, которые сыграли немалую роль во втором туре выборов, переориентировавшись на поддержку А. С. Ищенко.

Учитывая высокую значимость Приморского края для федерального центра, фигура нового кандидата должна была иметь высокий уровень доверия в руководстве страны и налаженные отношения с крупнейшими федеральными корпорациями, от которых зависит развитие региона. В связи с этим, по мнению А. А. Пожалова и М. Ю. Виноградова, О. Н. Кожемяко - наиболее подходящий кандидат. Ведь он известен как политический тяжеловес и антикризисный менеджер, понимающий специфическую эстетику поведения дальневосточных элит (Антикризисный глава ..., 2018: Электр. ресурс).

Необходимо отметить, что 3 октября 2018 г. депутаты Законодательного Собрания Приморского края на внеочередном заседании сразу в трех чтениях приняли поправки в Избирательный кодекс Приморского края, разрешающие самовыдвиженцам участвовать в выборах губернатора (Приморские депутаты ... , 2018: Электр. ресурс).

В Республике Хакасия по результатам первого тура кандидат от партии 
Научные труды Московского гуманитарного университета 2019 № 1

КПРФ В. О. Коновалов занял первое место, набрав 44,81\%. За действующего главу региона, кандидата от партии «Единая Россия»,

В. М. Зимина проголосовали 32,42 \% избирателей. За 2 дня до второго тура голосования выборов В. М. Зимин снял свою кандидатуру.

За 10 дней до второго тура голосования избирательная комиссия Республики Хакасия на основании представления прокуратуры приняла решение направить в Верховый суд Республики Хакассии иск об отмене регистрации В. О. Коновалова в связи с неверным указанием в документах наименования регионального отделения партии (Суд отложил ... , 2018: Электр. ресурс).

Однако, позднее избирательная комиссия Республики Хакасия отозвала свой иск и Верховный суд Хакассии прекратил производство по делу (Верховный суд Хакасии ..., 2018: Электр. ресурс).

По итогам второго тура В. О. Коновалов (единственный кандидат) одержал победу, получив поддержку 57,57\% голов избирателей. Для победы ему необходимо было набрать более $50 \%$ голосов избирателей. Явка во втором туре оказалась на 5\% выше, чем в первом туре, - около 41\% (Выборы в Хакасии..., 2018: Электр. ресурс).

Далее целесообразно рассмотреть результаты партий на выборах.

По сравнению с 2013 г. самое сильное падение - на 24,64\% - зафиксировано по итогам кампании в Законодательное собрание Ульяновской области.

Однако, в двух регионах партия «Единая Россия» улучшила свой результат по сравнению с предыдущими выборами: в Якутской области партия получила 53,35 против 47,41\% на прошлых выборах (На выборах в Госсобрание Якутии ..., 2018: Электр. ресурс).

В Республике Калмыкии прирост еще более впечатляющий $-68,58$ против 51,34\% по итогам предыдущей кампании.

При этом в трех регионах на выборах в глав регионов (Иркутская и Ульяновская области и в Республика Хакасия) партия «Единая Россия» проиграла избирательную кампанию партии КПРФ.

Иркутская область для партии «Единая Россия» была одним из самых сложных регионов при проведении избирательной кампании регионов поскольку там традиционно сильны позиции партии КПРФ, а во главе региона - губернатор от партии КПРФ (С. Г. Левченко).

Необходимо отметить, что Якутск - единственный случай на данных выборах, где на выборах мэра победил оппозиционный кандидат от партии «Партия возрождения России» С. В. Авксентьева.

По мнению политолога А. А. Пожалова, наиболее вероятная причина ее победы на выборах - это реакция на недопуск на выборы популярного оппозиционного городского политика В. Ю. Федорова. Кроме того, эксперты полагают, что еще одной причиной проигрыша партии «Единая Россия» 
на выборах глав регионов стала общественная реакция на федеральные реформы (Назад в нулевые ... , 2018: Электр. ресурс).

В заключении следует подвести итоги проведенного анализа:

В истории формирования корпуса глав регионов следует выделить несколько этапов: первый этап - 1992-1996 гг., второй этап - 1996-2005 гг., третий этап - 2005-2012 гг., четвертый этап - с 2012 года и по настоящее время.

Для Российской Федерации характерен поиск наиболее оптимального способа избрания губернаторов. В целом изменение системы формирования корпуса глав регионов обуславливается соотношением политических сил по линии «Центр - регионы». На выборах глав регионов в 2018 г. в общей сложности были выдвинуты 172 кандидата (147 - от 34 политических партий и 25 - в порядке самовыдвижения). Из них избирательными комиссиями субъектов Российской Федерации зарегистрированы 102 претендента - 99 от 16 партий и три самовыдвиженца. Наибольшее количество кандидатов баллотировалось от партии ЛДПР (20), партии «Единая Россия» и «Справедливой России» (по 19), КПРФ (17) и от Партии роста (7);

В ходе региональных кампаний в 2018 г. оппозиционные партии не проявили себя достаточно ярко, то есть не использовали потенциал недовольства избирателей, в том числе планируемым повышением пенсионного возраста.

Политологи полагают, что единый день голосования 2018 г. не настолько предсказуем, как раньше. По итогам единого дня голосования, в первом туре не сумели победить губернаторы четырех регионов (Владимировская область, Приморский край, Республика Хакасия, Хабаровский край).

В последний раз выборы в два тура проходили в Российской Федерации в 2015 г. Однако, сразу несколько вторых туров на губернаторских кампаниях - явление для современной России фактически уникальное. Такого не было с 2004 г., когда был принят закон об отмене прямых выборов губернаторов. После отмены результатов второго тура выборов глав регионов в Приморском крае произошла смена врио главы региона. Политологи не были уверены, что даже имеющего опыт антикризисного управления O. Н. Кожемяко ждет легкая победа на новых выборах.

Назначение О. Н. Кожемяко врио главы региона и выдвижение его в качестве кандидата на новых выборах поднимает два вопроса: насколько жители Приморского края примут нового представителя власти и согласятся ли на это местные элиты. Еще одним результатом выборов стало изменение в списке партий, которые освобождены от необходимости собирать подписи для выборов в Государственную Думу.

В целом, можно сделать вывод, что партии и кандидаты во время избирательной кампании 2018 г. не совсем эффективно применили политиче- 
ские технологии. Тем самым они упустили свои шансы в данной избирательной кампании получить поддержку большего числа голосов избирателей. Особенно это касается оппозиционных партий.

Также неэффективное применение политических технологий привело к тому в трех регионах на выборах в глав регионов (Иркутская и Ульяновская области и в Республика Хакасия) партия «Единая Россия» проиграла избирательную кампанию партии КПРФ.

Таким образом, очевидно, что всем кандидатам и партиям необходимо активно применять политические технологии в честной борьбе за голова избирателей. В таком случае, вероятно, следующие избирательные кампании на выборах глав регионах будут более яркими.

\section{СПИСОК ЛИТЕРАТУРЫ}

Антикризисный глава Кому Кремль поручил борьбу за Приморье (2018) [Электронный ресурс] // Информационное агентство «РБК». 26 сентября. URL: https://www.rbc.ru/newspaper/2018/09/27/5baba75d9a794746e03 0c764 (дата обращения 02.10.2018).

Глава ВЦИОМ считает, что ярких лидеров оппозиции на региональных выборах этого года нет (2018) [Электронный ресурс] // ИТАР-ТАСС. 3 сентября. URL: https://tass.ru/politika/5517497 (дата обращения 01.10.2018).

Верховный суд Хакасии прекратил рассмотрение иска о снятии кандидата от КПРФ Коновалова (2018) [Электронный ресурс] // ИТАР-ТАСС. 15 октября. URL: https://tass.ru/politika/5674215 (дата обращения 01.03.2019).

Выборы в Хакасии выиграл коммунист Коновалов (2018) [Электронный peсурс] // Ведомости. 11 ноября. URL: https://www.vedomosti.ru/politics/ articles/2018/11/11/786103-vibori-hakasii-viigral-kommunist (дата обращения: 01.03.2019).

Ланцов, С. А. (2018) Политология: учебник для академического бакалавриата. 2-е изд., испр. и доп. М. : Издательство Юрайт. 454 с.

Мамаева, Ю.А. (2015) Еще раз о выборах глав субъектов Российской Федерации // Российское право: образование, практика, наука. № 2. С. 25-30.

Мухаметов, Р. С. (2016) Этапы формирования корпуса губернаторов в России // Вопросы управления. № 2. С. 44-48.

Назад в нулевые: почему «Единая Россия» и губернаторы теряют регионы (2018) [Электронный ресурс] // Информационное агентство «РБК». 10 сентября. URL: https://www.rbc.ru/politics/10/09/2018/5b9648c09a794708 7ca2d013 (дата обращения 02.10.2018).

На выборах в Госсобрание Якутии «Единая Россия» проиграла в трети округов (2018) [Электронный ресурс] // ИA REGNUM. 10 сентября. URL: https://regnum.ru/news/2478754.html (дата обращения 11.10.2018). 
Победившего в Хакасии коммуниста хотят снять с выборов. К чему это приведет (2018) [Электронный ресурс] // Русская служба Би-би-си. 11 октября. URL: https://www.bbc.com/russian/news-45822520 (дата обращения 16.10.2018).

Приморские депутаты приняли закон об участии самовыдвиженцев в выборах губернатора, но не назначили дату голосования (2018) [Электронный ресурс] // 000 «ВЛ Новости». 3 октября. URL: https://www.newsvl.ru/ vlad/2018/10/03/174273/ (дата обращения 10.10.2018).

Сергей Фургал победил на выборах губернатора Хабаровского края (2018) [Электронный ресурс] // АО ИД «Комсомольская правда». 23 сентября. URL: https://www.kp.ru/online/news/3244425/ (дата обращения 01.10.2018).

Суд отложил рассмотрение иска избиркома о снятии Коновалова с выборов в Хакасии (2018) [Электронный ресурс] // ИНТЕРФАКС. 12 октября. URL: https://www.interfax.ru/russia/633092 (дата обращения 15.10.2018).

Эксперт назвал субъекты РФ с трудными условиями для кампаний глав регионов (2018) [Электронный ресурс] // ИTAP-TACC. 3 сентября. URL: https://tass.ru/politika/5518541 (дата обращения 01.10.2018).

Шабров, О. Ф. (2012) Политические технологии // Знание. Понимание. Умение. № 4. С. 328.-330.

Юсубов, Э. С. (2015) Избирательные системы на муниципальных выборах: теория и практика применения // Российское право: образование, практика, наука. № 4. С. 45-50.

Дата поступления: 30.11.2018 2.

Махора Екатерина Витальевна - аспирант кафедры философии, культурологии и политологии Московского гуманитарного университета. Адрес: 111395, Россия, г. Москва, ул. Юности, д. 5 . Тел.: +7 (985) 265-43-97. Эл. адрес: katrinmak17@rambler.ru. Научный руководитель - д-р полит. н., профессор В. И. Буренко.

Makhora Ekaterina Vitalievna, Postgraduate Student, Department of Philosophy, Culturology and Political Studies, Moscow University for the Humanities. Postal address: 5, Yunosti St., Moscow, Russian Federation, 111395. Tel.: +7 (985) 265-43-97. E-mail: katrinmak17@rambler.ru. Scientific Adviser V. I. Burenko, Doctor of Political Studies, Professor. 


\section{Для цитирования:}

Махора Е. В. Избирательное законодательство как разновидность политической технологии [Электронный ресурс] // Научные труды Московского гуманитарного университета. 2019. № 1. URL: http://journals.mosgu.ru/trudy/article/view/944 (дата обращения: дд.мм.гг.). DOI: 10.17805/trudy.2019.1.15 